\title{
Guidelines for virological and non-viral serological examination of specimens in routine diagnostic microbiological laboratories
}

\author{
J Francis, S P Barrett, M M Ogilvie, S Sutherland
}

J Clin Pathol 2004;57:1-5

Viral examination is routinely carried out in most routine diagnostic microbiology laboratories. Most often, this comprises the detection of viral antigens and antibodies, and less commonly the isolation of viruses and the detection of viral nucleic acids. However, there are no standards or guidelines available for processing these specimens in routine diagnostic laboratories or for referral to specialist virology centres or units. Clinical Pathology Accreditation (CPA) has defined standards for assessing the quality of service provided by laboratories, but these do not include the scientific and technical aspects of provision of service. The Association of Medical Microbiologists has recently published Standards for Laboratory practice in medical microbiology, which covers scientific and technical aspects of provision of microbiology service, mainly bacteriological examination of specimens in routine diagnostic microbiology laboratories. These guidelines are complementary to the CPA guidelines and aim to ensure a consistent and high quality service. This article presents guidelines for the examination of specimens for the diagnosis of viral infections.

See end of article for authors' affiliations

Correspondence to: Dr J Francis, Department of Microbiology, Rotherham General Hospitals NHS Trust, Moorgate road, Rotherham S60 2UD, UK; josephine.francis@ rothgen.nhs.uk

Accepted for publication 27 June 2003
$\mathrm{V}$ rological examination is routinely carried out in most diagnostic microbiology laboratories. Most often this comprises the detection of viral antigens and antibodies, and less commonly the isolation of viruses and the detection of viral nucleic acids. Nowadays, some of these virological investigations are carried out by experienced biomedical staff in routine diagnostic microbiology laboratories. However, some virological diagnostic procedures/tests require expertise that is only available in specialist virology centres or units (including some reference laboratories or academic research units).

Specialist virology centres are directed by clinically qualified, professionally trained, consultant virologists. These specialist centres are accredited for the provision of a comprehensive diagnostic virology service and for training of both clinical and scientific laboratory staff. These specialist centres should preferably be active in research in relevant diagnostic fields and should be able to provide specialist services and expertise relevant to local needs. Smaller units with single handed consultant virologists also exist; both centres and units have recently formed the UK Clinical Virology Network and recommended a strategy for clinical virology in the UK (http:// www.clinical-virology.org).

All virology services, irrespective of site, should provide timely reports of primary screening and, if undertaken, timely confirmatory testing. They should be consultant led and provide 24 hour clinical support for the interpretation of results, patient management, antiviral treatment, virology support for occupational health, and control of infection activity in the local provider unit(s).

\section{PROVISION OF VIROLOGY SERVICE} Standard

Virological services should be available in the laboratory itself or by arrangement with another laboratory. An on call service should be provided.

\section{Criteria}

- The service should be tailored to the number and type of clinical units served by the hospital. The staff providing the service should be appropriately trained and continually updated.

- All antenatal clinics should have easy access to the full range of viral screening tests.

- All tertiary units with organ transplant services, or regional neonatal units, should have facilities readily available for culture, virus detection, nucleic acid detection, and serological testing.

- An out of hours virology service should be available. This should include clinical advice and interpretation of results.

- If the test is not available on site, there should be arrangements with another laboratory, normally a specialist virology centre, for the

Abbreviations: $\mathrm{HBsAg}$, hepatitis $B$ surface antigen; $\mathrm{HBV} /$ $\mathrm{HCV}$, hepatitis $B / C$ virus; HIV, human immunodeficiency virus; NEQAS, National External Quality Assessment Scheme; VZV, varicella zoster virus 
provision of virological tests and out of hours service. See tests available, appendices A and B.

\section{COLLECTION AND TRANSPORT OF SPECIMENS Standard}

The specimens should be collected, transported, and stored in a manner that will guarantee the best possible results within the testing systems available (appendix C). ${ }^{1-3}$

\section{Criteria}

- The nature of the specimen and timing of its collection should be appropriate, and details of date of collection of the specimen, and relevant clinical data including any antiviral chemotherapy should be documented.

- Swab specimens for viral culture should be transported in appropriate viral transport medium and should comply with local protocols. All samples should be transported safely.

- Specimens for culture should be held at least until the final report has been sent out. These specimens should be stored at $-70^{\circ} \mathrm{C}$, except urine for cytomegalovirus, which should be kept at $4^{\circ} \mathrm{C}$.

- Serum (or plasma) should be stored at $-20^{\circ} \mathrm{C}$ unless nucleic acid detection is required such as for hepatitis C virus (HCV) or human immunodeficiency virus (HIV) viral load, in which case $-70^{\circ} \mathrm{C}$ is recommended. Antenatal sera from pregnant women should be stored for at least one year. ${ }^{4}$

\section{METHODS FOR VIRAL DIAGNOSIS/SCREENING Standard}

The methods used for the detection of viral antigens, nucleic acids, or antibodies should be as sensitive and specific as feasible. ${ }^{5}$

\section{Criteria}

- Methods used to screen donors (of organs, cells, or tissues) should be highly sensitive and thus require careful selection, particularly for emergency work. It should be ensured that the need for speed does not compromise the sensitivity of the method.

- HIV testing requires high specificity and all results found to be positive by screening methods should have at least two confirmatory tests. A second sample should be requested for repeat testing. Testing for the other serious bloodborne viruses (HBV and HCV) requires similar care in the confirmation of positive results.

- Commercially available kits should be selected according to the following criteria:

- good performance in formal comparative evaluation

- recommended by expert working groups

- most frequently used in National External Quality Assessment Scheme (NEQAS) reports

- perform well in quality assurance programmes.

- Standards should not be reduced for the convenience of automation or cost without very careful consideration.

- The results of the method(s) should have achieved a satisfactory rating by NEQAS.

\section{REPORTING OF RESULTS \\ Standard}

The results should be available to the clinician as appropriate to the clinical needs. Important results should be telephoned. Systems of communication to the user should be timely and helpful. ${ }^{6}$ Notification of epidemiologically relevant findings to local and regional public health should be prompt.

\section{Criteria}

- Rapid turnaround times for viral serology may be affected by financial constraints because of the need to ensure appropriate batch sizes. Cost benefit should be taken into account and documented in a locally agreed protocol.

- Emergency (or urgent) specimens: these should be tested immediately and the first results should be available in two to three hours.

- Priority specimens: these should be tested on the same day as receipt of the specimen and results should usually be available in 24-36 hours (for example, immunity to varicella).

- Routine specimens: these are processed according to set laboratory protocols in which the frequency of testing should be clearly documented.

- By automating methods, the need for processing specimens in a batch is reduced and allows for more flexibility and improved turnaround times.

- Infrequent requests should be referred to laboratories that perform such tests more often to ensure a more rapid and cost effective service.

- Urgent and clinically relevant results should be communicated within the same working day, preferably by telephone, in accordance with local protocol.

- Epidemiologically significant results should be reported to local consultant in communicable disease control/consultant in public health medicine and to Communicable Disease Surveillance Centre/Scottish Centre for Infection and Environmental Health in a timely manner.

\section{STORAGE OF SPECIMENS AND DATA \\ Standard}

The rules regarding storage of data or specimens should be clearly documented in a written protocol. ${ }^{48}$

\section{Criteria}

- Department of Health recommendations for personal health records $\mathrm{HC}(89) 20$ and HSG(94)11 require the storage of information in patient notes until their 25 th birthday for children and for a period of eight years for adults. Maternity records should be retained for 25 years.

- Because it is impracticable for laboratories to store even some of the results for 25 years, there should be provision to ensure that the reports reach the patient's notes.

- Whether on paper or electronically transferred, all requests, reports, and test performance results should be stored for as long as space permits, but at least for the period when the specimen is retrievable.

- For medicolegal reasons, certain records, such as antenatal, HIV, occupational health (sharps exposure related), organ, cell, and tissue donors, and post rape cases, should be kept for at least 10 years. Such specimens should be stored for a minimum of two years, with longer storage for some, as specified in the Royal College of Pathologists' guidelines (1999). ${ }^{4}$

- A protocol should exist for sending out written reports of results and the receipt of specimens received for storage.

\section{NON-VIRAL SEROLOGY \\ Introduction}

Serological tests are available for non-viral infections such as toxoplasmosis, syphilis, brucellosis, Lyme disease, and leptospirosis, in addition to other infections such as atypical 
pneumonia caused by mycoplasma and Legionella spp. Some tropical diseases and fungal infections may be diagnosed by serology. These tests are undertaken either as screening tests or have a diagnostic relevance, where isolation of the pathogen is difficult or not routinely undertaken. The value of such tests is limited by the specificity and reproducibility of the currently available testing systems.

Paired sera usually taken seven to 10 days apart are recommended for diagnosis, although a single sample is acceptable for screening purposes. Thus, for diagnostic purposes, the results are usually retrospective, but where a fourfold or greater rise in titre is noted between the acute and convalescent samples these have a confirmatory value. Viral specific IgM antibody may be detected in some infections, providing a diagnosis for recent primary infection with EBV or hepatitis A, for instance.

See appendix D for diagnostic and screening tests available.

\section{COLLECTION OF SPECIMENS}

\section{Standard}

Diagnostic serological tests should be performed on paired sera taken seven to 10 days apart. Provision should be made for screening of antenatal patients for syphilis, in addition to rubella, HBV, and HIV, or in accordance with local protocol.

\section{Criteria}

- An acute serum sample should be collected when the patient first presents clinically, ideally at the same time as taking a blood culture. A convalescent serum sample should be collected seven to 10 days later.

- In exceptional circumstances, the second (convalescent) sample may be collected sooner, after discussion with the consultant medical microbiologist or deputy.

- A single sample may be processed after consultation with the consultant medical microbiologist or deputy.

- The request form should contain clinically relevant information, with dates of onset of the disease or date of exposure to the infectious agent.

\section{PROCESSING OF SPECIMENS FOR SEROLOGICAL EXAMINATION \\ Standard}

The test process should be specific, accurate, and reproducible and should be validated by a recognised method. The clinical relevance of the results should be confirmed before issuing a final report. ${ }^{5}$

\section{Criteria}

- Non-specific reactions and crossreactions should be minimised. If such reactions occur there should be mechanisms to identify them and interpret results accordingly.

- Where little alternative to diagnosis exists, the consultant medical microbiologist's opinion should be sought before proceeding.

- The results of the method(s) should have achieved a satisfactory rating by NEQAS.

- Safety issues must always be taken into account when handling microbiology specimens or cultures. Universal precautions should be observed.

\section{SCREENING TESTS \\ Standard}

Screening tests require a single serum sample to be tested with a validated method that is specific and reproducible. It is strongly recommended that clinically relevant results should be confirmed before issuing a final report.

\section{Criteria}

- Screening of antenatal patients requires a large number of specimens to be processed. The method should be specific and reproducible because low level non-specific reactions may be encountered with some assays in antenatal sera.

- All tests/methods used should be validated.

- Provisions should be made for confirmatory tests that are specific, accurate, and reproducible.

\section{REPORTING OF RESULTS \\ Standard}

Reports on screening tests should be available within one week, or in accordance with the local protocol. Confirmatory tests should be available within two weeks, or as agreed locally.

\section{Criteria}

- Screening for antenatal clinics should be available as soon as possible, so that clinically relevant results may be dealt with appropriately without delay.

- Confirmatory tests should be available at the earliest opportunity and should be reported to the clinical staff. Where such tests are referred elsewhere, provision should be made to receive reports within a clinically acceptable time frame.

- Clinically relevant reports should be communicated to the appropriate clinician either by the consultant medical microbiologist or deputy. Appropriate clinical advice should be available.

- The reports should contain the normal range for the results issued. Abnormal results should be commented upon by the consultant medical microbiologist or deputy, or in accordance with the local protocol.

- The report should be clearly laid out and readily understood by the clinical staff.

\section{INTERPRETATION OF RESULTS \\ Standard}

Serological tests that are of dubious clinical importance should not be performed without consultation with the consultant medical microbiologist. Advice on appropriate testing should be available and the local protocols should contain a list of screening and diagnostic tests performed.

\section{Criteria}

- The relevance of requests for certain serological tests requires careful evaluation and this should be done by the consultant medical microbiologist or deputy.

- The laboratory should have protocols that document the serological tests for screening, diagnosis, and confirmation. The local protocol should state turnaround times for all reports.

- The consultant medical microbiologist should be involved in drawing up protocols for laboratory tests with the clinicians.

- The consultant medical microbiologist should advise on the appropriateness of various tests available and is ultimately responsible for reports issued by the laboratory.

\footnotetext{
Authors' affiliations

J Francis, ULH NHS Trust, Grantham District Hospital, Lincolnshire NG31 8DG, UK

S P Barrett, Charing Cross Hospital, London, UK

M M Ogilvie, University of Edinburgh Medical School, Edinburgh EH8 9AG, UK

S Sutherland, University of Edinburgh Medical School (retired)
} 
APPENDIX A

Microbiology laboratories providing routine diagnostic service could undertake the following virological tests.

- Antenatal

- rubella immunity screen

- hepatitis B surface antigen (HBsAg) screen

- HIV antibody screen (usefully on same serum sample as used for syphilis screen)

- anti-varicella zoster virus (VZV) antibody screen

- Paediatrics

- rotavirus antigen detection

- respiratory syncytial virus antigen detection

- Genitourinary medicine

- HIV antibody screen
- HBsAg screen

- anti-HBV antibody titre

- Occupational health

- HBsAg screen

- anti-HBV antibody titre

- anti-VZV antibody screen

- rubella immunity screen

- Other tests available

- cytomegalovirus antibody screen

- hepatitis A $\lg G, \lg M$

- HBsAg screen

- hepatitis C antibody screen

- heterophile antibody

Confirmation and further testing of any of the above as appropriate should be done by a specialist virology centre.

\section{APPENDIX B}

Table 1 Tests that should be available in, or accessible to, a specialist virology centre

\begin{tabular}{|c|c|}
\hline Organism & Tests \\
\hline \multicolumn{2}{|l|}{ Hepatitis viruses } \\
\hline HAV & $\lg G$ and $\lg M$ \\
\hline HBV & Full serological markers, HBV DNA and antiviral sensitivity \\
\hline $\mathrm{HCV}$ & HCV antibodies, HCV RNA, HCV genotyping \\
\hline HDV & HDV antibodies, HDV antigen \\
\hline HEV & HEV antibodies \\
\hline \multicolumn{2}{|l|}{ Retroviruses } \\
\hline \multirow[t]{3}{*}{ HIV-1 and 2} & Antibodies, p24 antigen \\
\hline & HIV 1 and 2 RNA, viral load including an ultrasensitive assay \\
\hline & HIV 1 and 2 proviral DNA, HIV antiviral resistance markers \\
\hline HTLV-1 and 2 & Antibodies to HTLV-1 and 2, proviral DNA \\
\hline \multicolumn{2}{|l|}{ Herpesviruses } \\
\hline CMV & $\begin{array}{l}\text { Culture, rapid culture, early antigen detection, direct antigen detection, CMV DNA or } \\
\text { mRNA, IgG and IgM antibodies, antiviral sensitivity }\end{array}$ \\
\hline EBV & $\begin{array}{l}\text { Heterophile antibody, full EBV serology, EBV DNA, in situ detection of EBV mRNA and } \\
\text { proteins }\end{array}$ \\
\hline HSV & Culture, specific antigen detection, HSV antibodies, HSV DNA \\
\hline HHV-6 & Culture, antigen detection, $\lg G$, and $\lg M, \mathrm{HHV}-6$ DNA \\
\hline VZV & Direct antigen, culture, $\lg G, \lg M$, VZV DNA \\
\hline \multicolumn{2}{|r|}{ 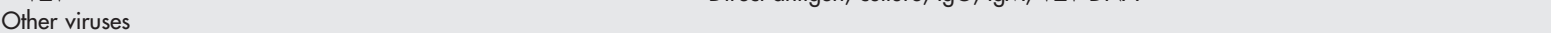 } \\
\hline Adenovirus & Culture, EM, direct antigen detection, serology \\
\hline Arboviruses & Serology, molecular tests, isolation \\
\hline Enteroviruses & Culture, enterovirus $\lg M$, enteroviral RNA \\
\hline \multicolumn{2}{|l|}{ Haemorrhagic fever } \\
\hline Viruses & Culture, serology, molecular tests \\
\hline Measles & Serology, culture, molecular tests \\
\hline Molluscum contagiosum & EM \\
\hline Mumps & Culture, serology, molecular tests \\
\hline Orf & EM \\
\hline HPV & EM, HPV DNA \\
\hline Parvovirus & $\lg G, \lg M$, parvovirus $B 19$ DNA \\
\hline BKV and JCV & EM, serology, culture, DNA detection \\
\hline $\begin{array}{l}\text { Respiratory viruses (such as influenza } A \text { and } B \text {, parainfluenza } \\
\text { viruses, SARS-CoV, and RSV) and new human metapneumovirus }\end{array}$ & $\begin{array}{l}\text { Direct antigen detection, culture, serology, subtyping, nucleic acid detection, molecular } \\
\text { tests }\end{array}$ \\
\hline Rotaviruses and other gut viruses (astrovirus, calicivirus, & Antigen detection, EM, RNA detection \\
\hline Rubella & IgG, IgM, rubella RNA, antibody avidity \\
\hline \multicolumn{2}{|l|}{ Non-viral agents } \\
\hline Chlamydia trachomatis & DNA detection, antigen detection, culture, serology \\
\hline Chlamydia psittaci & Serology, DNA detection \\
\hline Chlamydia pneumoniae & Serology, DNA detection \\
\hline Coxiella burnetii & Serology \\
\hline Legionella & Antigen detection (urine and $\mathrm{BAL}$ ), serology \\
\hline Mycoplasma pneumoniae & Serology (often performed in microbiology laboratories) \\
\hline Pneumocystis carinii & Antigen detection \\
\hline$Q$ fever & Serology \\
\hline Rickettsia & Serology \\
\hline Toxoplasma & Serology, DNA detection \\
\hline
\end{tabular}

BAL, broncho-alveolar lavage; BKV, polyoma BK virus; CMV, cytomegalovirus; EBV, Epstein-Barr virus; EM, electron microscopy; $\mathrm{HAV} / \mathrm{HBV} / \mathrm{HCV} / \mathrm{HDV} / \mathrm{HEV}$, hepatitis $\mathrm{A} / \mathrm{B} / \mathrm{C} / \mathrm{D} / \mathrm{E}$ virus; HHV, human herpesvirus; HIV, human immunodeficiency virus; HPV, human papillomavirus; HSV, herpes simplex virus; HTLV, human T cell leukaemia virus; JCV, polyoma JC virus; RSV, respiratory syncytial virus; SARS-CoV, severe acute respiratory syndrome associated coronavirus; VZV, varicella zoster virus. 


\section{APPENDIX C}

Table 2 Collection and transport of virology specimens

\begin{tabular}{|c|c|c|}
\hline Specimen required & Container & Virus/organism \\
\hline \multicolumn{3}{|l|}{ Specimens for isolation } \\
\hline Swabs & VTM & HSV, VZV, adenovirus, others \\
\hline Faeces & Sterile leak proof container & Enteroviruses \\
\hline Biopsy & Sterile phosphate buffered saline & Many \\
\hline Blood & Preservative free heparin or EDTA & CMV \\
\hline Urine & Sterile leak proof container & CMV \\
\hline Chlamydial swabs: cervical/urethral/eye & Chlamydial transport medium and not VTM & Chlamydia trachomatis \\
\hline $\begin{array}{l}\text { Nasal washing, tracheal aspirate, } \\
\text { respiratory specimens/BAL }\end{array}$ & Sterile leak proof container & Respiratory viruses \\
\hline CSF & Sterile leak proof container & Mumps, enterovirus, HSV-1, HSV-2 \\
\hline \multicolumn{3}{|l|}{ Antigen detection } \\
\hline Nasopharyngeal aspirates & Sterile leak proof container & Respiratory viruses, RSV \\
\hline Conjunctival/cervical/urethral scrape & Chlamydial ELISA transport medium & Chlamydia trachomatis \\
\hline Swab from base of lesion & VTM & VZV, HSV \\
\hline Faeces & Sterile leak proof container & Rotavirus, adenovirus $40 / 41$ \\
\hline Serum/plasma & Plain tube clotted blood & $\mathrm{HBsAg}, \mathrm{HBeAg}, \mathrm{HIV}$ p24Ag \\
\hline \multicolumn{3}{|l|}{ Antibody detection } \\
\hline Clotted blood for serum & Plain tube (white top); 5-10 ml & $\mathrm{HAV}, \mathrm{HBV}, \mathrm{HCV}, \mathrm{HIV}$ etc. \\
\hline \multicolumn{3}{|l|}{ Electron microscopy } \\
\hline Vesicular lesion scrape & Two glass slides & HSV/VZV, poxviruses \\
\hline Core of lesion & Sterile leak proof container & Poxviruses (molluscum) \\
\hline Faeces & Sterile leak proof container & $\begin{array}{l}\text { Rotavirus; adenovirus, astrovirus, calicivirus, Norwalk- } \\
\text { like viruses }\end{array}$ \\
\hline \multicolumn{3}{|l|}{ Nucleic acid detection } \\
\hline CSF & Sterile leak proof container & HSV, VZV, HHV-6, enteroviruses, JC \\
\hline Peripheral blood & Preservative free heparin or EDTA & $\begin{array}{l}\text { HCV, HIV RNA, HBV DNA, CMV, parvovirus, } \\
\text { toxoplasma DNA }\end{array}$ \\
\hline Cervical/urethral conjunctival cells & Transport medium appropriate for test & Papillomavirus, chlamydia \\
\hline Urine & Sterile leak proof container & Chlamydia trachomatis \\
\hline Faeces & Sterile leak proof container & SRSV \\
\hline
\end{tabular}

BAL, broncho-alveolar lavage; CMV, cyłomegalovirus; CSF, cerebrospinal fluid; ELISA, enzyme linked immunosorbent assay; HAV/HBV/HCV, hepatitis A/B/C virus; $\mathrm{HbeAg}$, hepatitis B antigen; HHV, human herpesvirus; HIV, human immunodeficiency virus; $H S V$, herpes simplex virus; $H B s A g$, hepatitis $B$ surface antigen; RSV, respiratory syncytial virus; SRSV, small round spherical virus; VSV, varicella zoster virus; VTM, virus transport medium.

\section{APPENDIX D}

Table 3 Serological tests available for diagnosis and screening

\begin{tabular}{ll}
\hline Diagnostic tests & Screening tests \\
\hline Mycoplasma & Syphilis \\
Toxoplasma & Toxoplasma \\
Legionella & \\
Leptospira & \\
Syphilis & \\
Lyme disease (borrelia) & \\
Brucella & \\
$Q$ fever (coxiella) & \\
\hline
\end{tabular}

\section{REFERENCES}

1 Standard E3. CPA standards for accreditation. Sheffield: Clinical Pathology Accreditation (UK) Ltd.

2 Standard E4. CPA standards for accreditation. Sheffield: Clinical Pathology Accreditation (UK) Ltd.
3 Standard F2. CPA standards for accreditation. Sheffield: Clinical Pathology Accreditation (UK) Ltd.

4 The retention and storage of pathology reports and archives. London: Royal College of Pathology, Feb 1999.

5 Standard G3. CPA standards for accreditation. Sheffield: Clinical Pathology Accreditation (UK) Ltd.

6 Standard G5. CPA standards for accreditation. Sheffield: Clinical Pathology Accreditation (UK) Ltd.

7 Preservation, retention and destruction of records, responsibilities of health authorities under the public records acts. London: Department of Health, Health Circular, $\mathrm{HC}(89) 20,1989$.

8 Standard A9. CPA standards for accreditation. Sheffield: Clinical Pathology Accreditation (UK) Ltd.

\section{FURTHER READING}

1 Roberts C, Kelsey MC, eds. Microbiology accreditation and quality assessment schemes in the UK: measuring up to the standards. London: Association of Medical Microbiologists, 1992

2 Medical and scientific staffing of National Health Service pathology departments. London: Royal College of Pathologists, June 1999.

3 Model job description for a consultant microbiologist and for a consultant virologist. London: Royal College of Pathologists, January 2002.

4 Quality standards in medical microbiology virology In: Bulletin of the Royal College of Pathologists, June 1993:10-12. 